\title{
Effect of passive stretching on the immobilized soleus muscle fiber morphology
}

E.L. Coutinho ${ }^{1}$,

A.R.S. Gomes ${ }^{1}$, C.N. França ${ }^{1}$, J. Oishi ${ }^{2}$, and T.F. Salvini ${ }^{1}$

\author{
${ }^{1}$ Unidade de Plasticidade Muscular, Laboratório de Neurociências, \\ Departamento de Fisioterapia, and ${ }^{2}$ Departamento de Estatística, \\ Universidade Federal de São Carlos, São Carlos, SP, Brasil
}

\begin{abstract}
Correspondence
T.F. Salvini

Departamento de Fisioterapia

Universidade Federal de São Carlos

13565-905 São Carlos, SP

Brasil

Fax: +55-16-3351-2081

E-mail: tania@power.ufscar.br

Part of this study was presented

in Abstract form at the XVII Annual

Meeting of the Federação de

Sociedades de Biologia Experimental,

Salvador, BA, Brazil, August 28-31,

2002.

Research supported by FAPESP.

E.L. Coutinho and A.R.S. Gomes are

recipients of $\mathrm{PhD}$ fellowships from

CAPES and FAPESP, respectively.

C.N. França is an undergraduate

fellow supported by $\mathrm{CNPq}$.
\end{abstract}

Received March 10, 2004

Accepted September 14, 2004

$\ldots \ldots \ldots \ldots \ldots \ldots . . \ldots$

\section{Abstract}

The aim of the present study was to determine the effect of stretching applied every 3 days to the soleus muscle immobilized in the shortened position on muscle fiber morphology. Eighteen 16-week-old Wistar rats were used and divided into three groups of 6 animals each: a) the left soleus muscle was immobilized in the shortened position for 3 weeks; b) during immobilization, the soleus was stretched for $40 \mathrm{~min}$ every 3 days; c) the non-immobilized soleus was only stretched. Left and right soleus muscles were examined. One portion of the soleus was frozen for histology and muscle fiber area evaluation, while the other portion was used to identify the number and length of serial sarcomeres. Immobilized muscles (group A) showed a significant decrease in weight $(44 \pm 6 \%)$, length $(19 \pm 7 \%)$, serial sarcomere number $(23 \pm 15 \%)$, and fiber area $(37 \pm 31 \%)$ compared to the contralateral muscles $(\mathrm{P}<0.05$, paired Student $t$-test). The immobilized and stretched soleus (group B) showed a similar reduction but milder muscle fiber atrophy compared to the only immobilized group ( $22 \pm 40$ vs $37 \pm 31 \%$, respectively; $\mathrm{P}<0.001$, ANOVA test). Muscles submitted only to stretching (group C) significantly increased the length $(5 \pm 2 \%)$, serial sarcomere number $(4 \pm 4 \%)$, and fiber area (16 $\pm 44 \%)$ compared to the contralateral muscles $(\mathrm{P}<0.05$, paired Student $t$-test). In conclusion, stretching applied every 3 days to immobilized muscles did not prevent the muscle shortening, but reduced muscle atrophy. Stretching sessions induced hypertrophic effects in the control muscles. These results support the use of muscle stretching in sports and rehabilitation.
An important question for physical rehabilitation is how to protect or to reduce the effects of immobilization on skeletal muscles, especially in muscles immobilized in the shortened position. It is well known that immobilization in a shortened position causes

\section{Introduction}

Key words

- Skeletal muscle

- Passive stretch

- Muscle immobilization

- Sarcomere number

- Muscle atrophy

- Muscle fiber area a loss of serial sarcomere number along the length of the muscle fibers, with a consequent shortening of muscle length (1-3). The reduction of serial sarcomere number is presumed to be a response to variations in the ideal functional length of the sarcomere, which affects normal sarcomere function. This process should occur in such a way that 
the remaining sarcomeres would maintain ideal functional length. The opposite occurs in the muscles immobilized in the lengthened position, in which the addition of serial sarcomeres enables the restoration of optimal sarcomere length $(1,3,4)$.

In addition to alterations in muscle length, a significant decrease in muscle strength and mass is also induced by immobilization, and can be observed within the first $48 \mathrm{~h}(5,6)$. It has been shown that soleus muscles held in the shortened position lose $37 \%$ of their mass after being immobilized for 7 days, whereas immobilization in the stretched position does not cause muscle fiber atrophy (7-9). It is also known that skeletal muscle stretching is very important not only to increase the joint range of motion, but also to prevent and treat injuries, thus being a therapeutic tool frequently used in physical rehabilitation and sports $(10,11)$. Muscle stretching is recognized as a very powerful stimulant of muscle longitudinal growth and muscle protein synthesis $(8,12,13)$.

Several studies have emphasized the importance of stretching to prevent connective tissue proliferation, muscle fiber atrophy, and the loss of serial sarcomeres in immobilized muscles $(2,12,13)$. Also, previous reports have indicated that stretching can induce muscle fiber radial hypertrophy and hyperplasia (14-16). Williams (2) evaluated the effects of intermittent stretching on muscles immobilized in the shortened position and showed that $30 \mathrm{~min}$ of stretching applied daily maintained the range of motion and prevented the loss of serial sarcomeres and connective tissue proliferation. Therefore, the frequency and duration of stretching applied to shortened muscles should be considered in such studies.

Although the effect of stretching on shortened muscle has already been studied for almost 30 years, some aspects have not been addressed in detail, mainly regarding the effect of periodic sessions of stretching recommended for rehabilitation and physical education programs aiming at the gain of flexibility in humans. For example, what is the effect of 2 or 3 sessions of stretching a week, frequently indicated for rehabilitation and sports activities, on shortened muscles and on muscles of normal length?

The stretching protocol proposed was chosen because it is frequently used in rehabilitation and sports programs to recover the muscle length of shortened muscles and also to maintain or improve human flexibility. Although there are several differences between rodent and human skeletal muscles, mainly in terms of protein turnover, the results of the present study can provide new information about the adaptation of skeletal muscles submitted to periodic sessions of stretching. To our knowledge, this is the first time that a protocol using this frequency and duration of muscle stretching is applied to skeletal muscle with subsequent morphological evaluation of muscle fibers.

The purpose of the present study was to assess the effect of stretching sessions applied every 3 days to the soleus muscle immobilized in the shortened position for 3 weeks on muscle fiber morphology.

\section{Material and Methods}

\section{Animal care and groups}

Eighteen 16-week-old male Wistar rats weighing $298 \pm 32 \mathrm{~g}$ were used. The animals were housed in plastic cages in a room kept at $23 \pm 2^{\circ} \mathrm{C}$ and a 12-h light-dark cycle. They had free access to water and standard food. The study was conducted in accordance to the Guide for Care and Use of Laboratory Animals of Universidade Federal de São Carlos. The rats were anesthetized by intraperitoneal injection of xylazine $(12 \mathrm{mg} / \mathrm{kg})$ and ketamine $(95 \mathrm{mg} / \mathrm{kg})$ for the application of an immobilization device, every time they were submitted to stretching, and during surgery to remove the muscles. After the experiment, the animals were killed by an anesthetic overdose. 
The animals were randomly divided into three groups of 6 rats each: a) the left hind limb was immobilized in order to hold the soleus muscle in the fully shortened position for 3 weeks; b) the left soleus was immobilized in the shortened position for 3 weeks, but each 3 days the immobilization was removed and the muscle maintained in the fully stretched position for $40 \mathrm{~min}$. After stretching, the hind limb was immobilized again to hold the soleus in the fully shortened position; c) the left soleus was only submitted to the sessions of passive stretching each 3 days for 3 weeks. In all groups, the contralateral right soleus was left intact and used for comparison.

\section{Immobilization procedure}

To keep the soleus muscle in the fully shortened position a device developed in our laboratory was used for the immobilization of the hind limb of rats. With this device, the ankle joint is fixed in full plantar flexion producing chronic muscle disuse, as a good alternative to the traditional methods of immobilization (for details, see Ref. 17). The device is made of steel mesh and cotton materials, and has some advantages when compared to a cast or plaster cast: it is cheaper and lighter and the same unit can be easily adjusted and used several times for the same animal or for animals of similar body weight. No skin ulceration or foot swelling was detected in the animals during the immobilization period. To stretch the soleus muscle, the left ankle of the animal was positioned in full dorsal flexion, fixed with tape, and maintained in this position for $40 \mathrm{~min}$. Immobilization was adjusted when necessary to guarantee a full plantar position.

\section{Morphology and sarcomere measurements}

Three weeks after the beginning of the experiments all animals were anesthetized and weighed and both the right and left soleus muscles were carefully dissected free from surrounding tissue. Subsequently, the tendons of the soleus muscle were clamped with the muscle in the resting position, which was defined as $\mathrm{L}_{\mathrm{o}}$, as previously reported by Ansved (18) and muscle length was determined. Each soleus muscle was then divided longitudinally into two similar parts: the medial one was used for histology, while the lateral portion was used for the sarcomere measurements.

The number and length of the sarcomeres along a single muscle fiber were determined by the method of Williams and Goldspink (6). The muscle was fixed in the resting position ( $\mathrm{L}_{\mathrm{o}}$ length) in $2.5 \%$ glutaraldehyde for $3 \mathrm{~h}$ and then removed, placed in 30\% $\mathrm{HNO}_{3}$ for two days, and stored in $50 \%$ glycerol. Next, five individual fibers of the whole muscle were teased from tendon-to-tendon from each soleus muscle and mounted and their length was measured using a caliper rule. The number and length of the sarcomeres along a $300-\mu \mathrm{m}$ portion were quantified at different points in the middle region of each single fiber using a projection microscope (Axiolab, Carl Zeiss, Oberkochen, Germany). The total number of sarcomeres in each muscle fiber was identified by the correlation between the number of sarcomeres identified along the $300-\mu \mathrm{m}$ portion and the total fiber length (19). In view of the conflicting reports on the literature about the sarcomere length along the muscle fibers, particularly at the ends of the stretched fibers $(6,21,22)$, in the present study we assumed that sarcomere length is homogeneous along the entire length of the muscle fiber.

For histology, the muscle was immediately frozen in isopentane pre-cooled in liquid nitrogen and stored at $-80^{\circ} \mathrm{C}$ in a freezer (Forma Scientific Inc., Marietta, OH, USA). Serial cross-sections $(10 \mu \mathrm{m})$ were then obtained from the middle part of the frozen muscles using a cryostat (Microm HE 505, Germany) and the histological cross-sections were stained with $1 \%$ Toluidine blue/1\% 
borax for the morphological evaluation of the muscles and fiber area measurement, as previously described (23-25).

\section{Muscle fiber area}

The cross-sectional area of 100 muscle fibers randomly chosen from the central region of one cross-section of each soleus muscle was measured using an Axiolab light microscope (Carl Zeiss) and software for

Figure 1. Rat soleus muscles stained with Toluidine blue. Panel A shows atrophic muscle fibers of soleus muscle immobilized in the shortened position for 3 weeks. Panel $B$ shows the contralateral muscle, which presents normal fibers but also signs of regenerated fibers such as split fibers (asterisks). Pane $C$, muscle fibers of soleus muscle immobilized and stretched every 3 days also present atrophy compared to the contralateral muscle (pane D). Note that the contralatera soleus (panel D) shows split fibers (asterisks) and fibers with centralized nuclei (arrows). Soleus muscle submitted only to sessions of stretching every 3 days (panel E) and the contralateral muscle (panel F) show muscle fibers of normal aspect. Bar $=75 \mu \mathrm{m}$ for all panels.
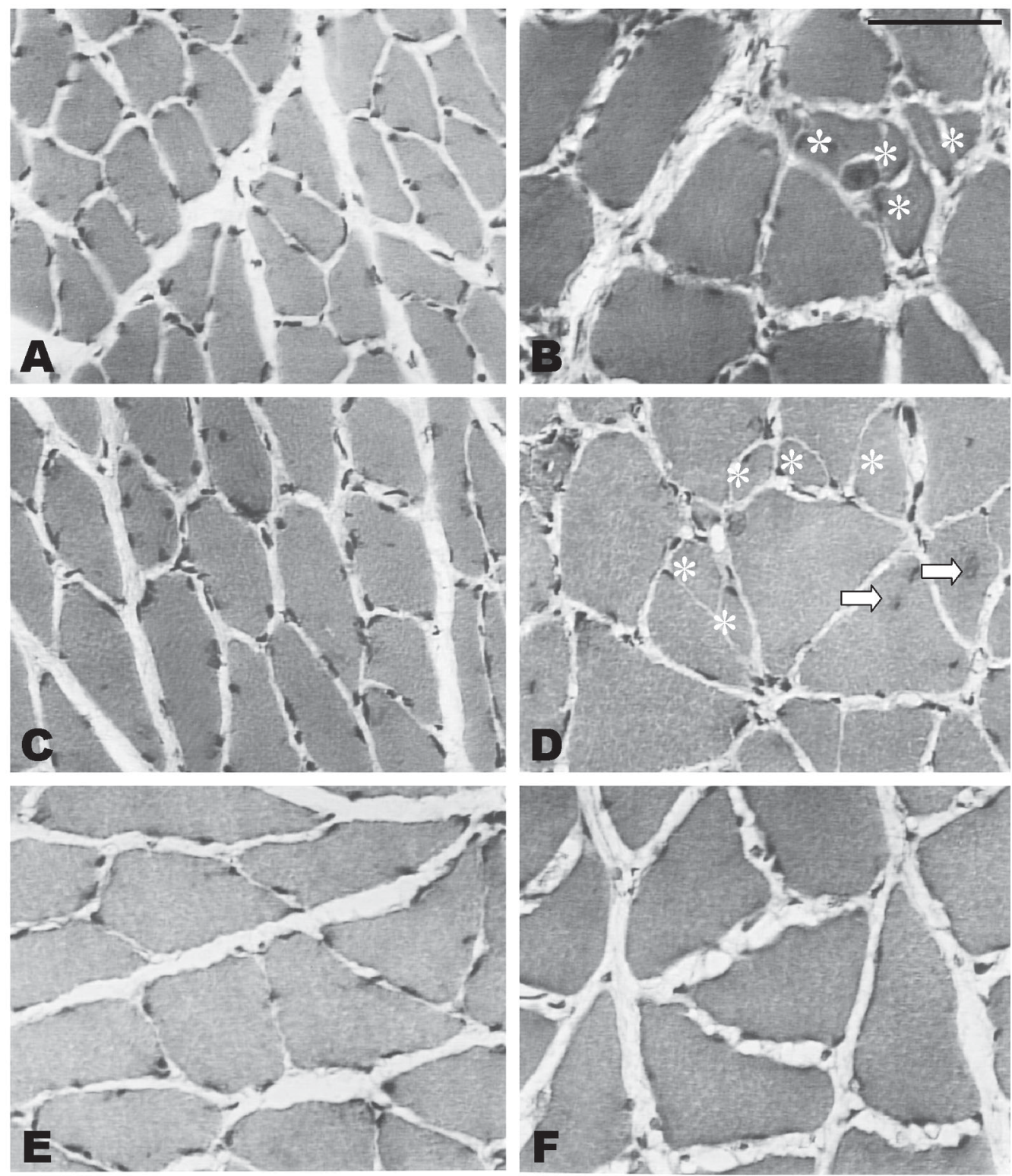

morphology (Axiovision 3.0.6 SP4, Carl Zeiss).

\section{Statistical analysis}

The paired Student $t$-test was used to compare the data for the right and left soleus of the same animals within each group. Possible differences among groups were determined by ANOVA and by the Duncan test, with the level of significance set at $5 \%(\mathrm{P} \leq 0.05)$. 


\section{Results}

\section{Histology}

Soleus muscles immobilized in the shortened position for 3 weeks presented muscle fiber atrophy (Figure 1A), when compared to the contralateral one (Figure 1B). Although most of the muscle fibers of the contralateral soleus showed a normal aspect, some muscle regions showed regenerated fibers characterized by the presence of split fibers (Figure 1B) and fibers with centralized nuclei. Immobilized and stretched soleus also showed muscle fiber atrophy (Figure 1C), while the contralateral muscles also presented regenerated fibers (Figure 1D). Soleus muscles only submitted to stretching and their contralateral muscles presented fibers of normal aspect (Figure 1E and F, respectively).

\section{Body weight}

Animals immobilized for 3 weeks lost 12 $\pm 6 \%$ of their body weight compared to the initial weight (from $291 \pm 33$ to $256 \pm 29 \mathrm{~g}$, $\mathrm{P}=0.01)$. The group immobilized and stretched every 3 days also lost $17 \pm 4 \%$ of their body weight (from $317 \pm 37$ to $264 \pm 29$ $\mathrm{g}$, respectively, $\mathrm{P}=0.001)$. In contrast, the non-immobilized group only submitted to stretching showed a $17 \pm 9 \%$ increase in body weight during the 3 weeks (from $290 \pm$ 25 to $343 \pm 27 \mathrm{~g}, \mathrm{P}=0.004$ ).

\section{Muscle weight}

Soleus muscles immobilized for 3 weeks lost $44 \pm 6 \%$ of their weight compared to the contralateral muscles $(0.13 \pm 0.04$ vs $0.19 \pm$ $0.3 \mathrm{~g}$, respectively, $\mathrm{P}=0.002$; Figure 2). Immobilized soleus stretched every 3 days also lost $46 \pm 5 \%$ of its weight compared to the contralateral one $(0.09 \pm 0.01$ vs $0.19 \pm$ 0.02 g, respectively, $\mathrm{P}<0.001$; Figure 2). In contrast, there were no changes in weight of the soleus muscle only submitted to the stretching sessions compared to the contralateral one $(0.17 \pm 0.02$ vs $0.18 \pm 0.03 \mathrm{~g}$, respectively, $\mathrm{P}=0.06$; Figure 2 ).

\section{Muscle length}

Immobilization in the shortened position reduced $19 \pm 7 \%$ of the soleus length compared to the contralateral muscle $(11 \pm 0.9 \mathrm{vs}$ $14 \pm 1.5 \mathrm{~mm}$, respectively, $\mathrm{P}=0.008$; Figure 2). Muscles immobilized and submitted to periodic stretching sessions showed a similar decline in muscle length $(21 \pm 8 \%)$ compared to the contralateral soleus $(12 \pm 2$ vs 15 $\pm 1 \mathrm{~mm}$, respectively, $\mathrm{P}=0.001$; Figure 2 ). There was no significant difference in the reduction of muscle length between the soleus muscles of the immobilized groups $(\mathrm{P}=$ 0.5 ). However, a $5 \pm 2 \%$ increase was found in the non-immobilized soleus submitted only to sessions of stretching $(15 \pm 0.7 v s 14 \pm 0.9$ $\mathrm{mm}$, respectively, $\mathrm{P}=0.006$; Figure 2 ).

\section{Serial sarcomere number}

The muscle fibers of soleus muscle immobilized for 3 weeks showed a $23 \pm 15 \%$

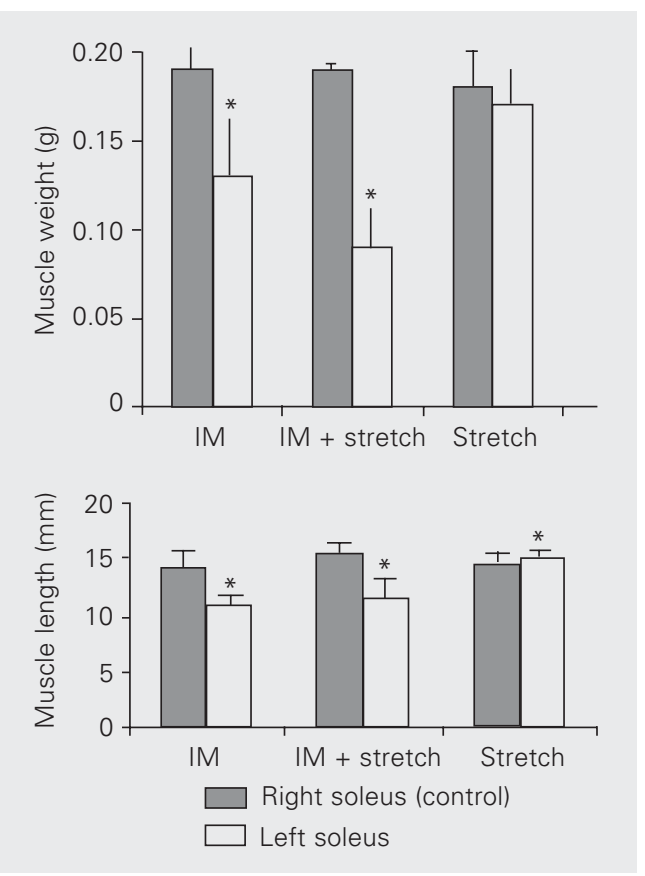

Figure 2. Effect of stretching on immobilized soleus muscle weight and length. IM = immobilized group: the left soleus was immobilized in the shortened position for 3 weeks; IM + stretch = immobilized + stretched group: the left soleus was immobilized for 3 weeks and stretched every 3 days; Stretch $=$ the left soleus was only stretched every 3 days. Data are reported as means \pm SD for 6 rats in each group. ${ }^{*} \mathrm{P}<0.05$ compared to the control contralateral right soleus muscle of the same animal (paired Student t-test). 
decrease in the number of serial sarcomeres compared to the contralateral muscles (5748 \pm 1103 vs $7517 \pm 797$, respectively, $\mathrm{P}<$ 0.001 ; Figure 3). Periodic stretching sessions applied to the immobilized soleus every 3 days did not prevent the loss of serial sarcomeres $(32 \pm 12 \%)$ compared to the contralateral muscle fibers $(5461 \pm 1103 v s$ $8029 \pm 422$, respectively, $\mathrm{P}<0.001$; Figure $3)$. No difference $(P=0.07)$ was found in the loss of serial number of sarcomeres between the muscle fibers of immobilized and immobilized/stretched muscles. Nevertheless, the non-immobilized soleus muscles stretched every 3 days showed a $4 \pm 4 \%$ increase in serial sarcomere number compared to the contralateral muscles $(7416 \pm 176$ vs $7138 \pm$ 283 , respectively, $\mathrm{P}=0.02$; Figure 3 ).

Figure 3. Effect of stretching on immobilized soleus muscle fiber area, serial sarcomere number, and sarcomere length. $\mathrm{IM}=\mathrm{im}$ mobilized group: the left soleus was immobilized for 3 weeks; $\mathrm{IM}+$ stretch = immobilized + stretched group: the left soleus was immobilized for 3 weeks and stretched every 3 days: Stretch $=$ the left soleus was only stretched every 3 days. Data are reported as means \pm SD for 6 rats in each group. ${ }^{*} \mathrm{P}<$ 0.05 compared to the control contralateral right soleus muscle (paired Student $t$-test). ${ }^{+} \mathrm{P}<0.05$ compared to the immobilized group (ANOVA).
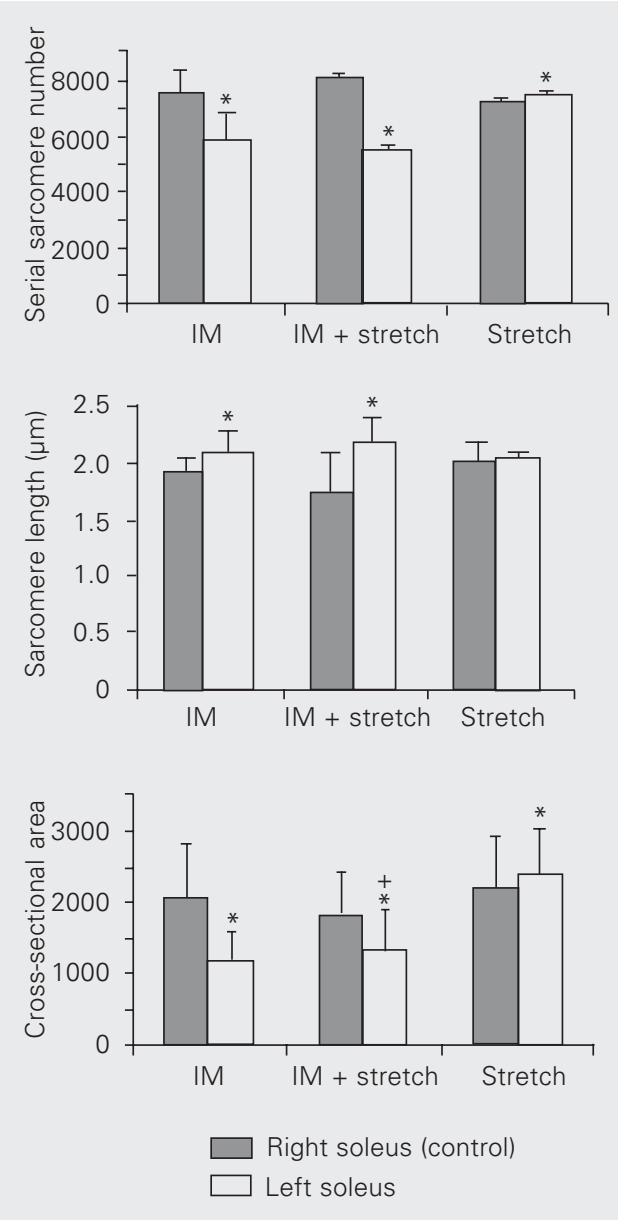

\section{Sarcomere length}

Sarcomere length increased in the muscle fibers of the immobilized soleus compared to the contralateral one $(2.1 \pm 0.1$ vs $1.9 \pm 0.1$ $\mu \mathrm{m}$, respectively, $\mathrm{P}<0.001$; Figure 3 ). A similar result was obtained for the muscles immobilized and stretched every 3 days, which also showed increased sarcomere length compared to the contralateral soleus $(2.2 \pm 0.08$ vs $1.9 \pm 0.05 \mu \mathrm{m}$, respectively, $\mathrm{P}$ $<0.001$; Figure 3).

In contrast, there was no change in the sarcomere length of soleus muscles only submitted to stretching compared to the contralateral muscles $(2.05 \pm 0.03$ vs $2.02 \pm 0.2$ $\mu \mathrm{m}$, respectively; Figure 3 ).

\section{Muscle fiber area}

The soleus muscles immobilized in the shortened position for 3 weeks showed a 37 $\pm 31 \%$ reduction in the cross-sectional area of the muscle fibers compared to the contralateral muscles $(1179 \pm 416$ vs $2084 \pm 728$ $\mu \mathrm{m}^{2}$, respectively, $\mathrm{P}<0.001$; Figure 3). Although cross-sectional atrophy was also found in the immobilized/stretched soleus muscles $(22 \pm 40 \%)$ compared to the contralateral muscles $(1334 \pm 575$ vs $1836 \pm 581$ $\mu \mathrm{m}^{2}$, respectively, $\mathrm{P}<0.001$; Figure 3 ), muscle fiber atrophy was lower compared to the muscles only immobilized $(\mathrm{P}<0.001)$. On the other hand, soleus muscles only submitted to passive stretching sessions showed an increase in muscle fiber area compared to the contralateral ones $(2383 \pm 657$ vs $2220 \pm$ $691 \mu \mathrm{m}^{2}$, respectively, $\mathrm{P}<0.001$; Figure 3).

\section{Discussion}

The results of this study showed that sessions of passive stretching applied three times a week for 40 min for 3 weeks to the immobilized shortened soleus of rats were not sufficient to prevent the loss of serial sarcomeres, but provided significant protec- 
tion against muscle fiber atrophy.

Also, it was interesting to note that normal non-immobilized muscles, which received only 3 sessions of stretching a week, showed an increase both in serial sarcomere number and in the cross-sectional area of the muscle fibers. These results indicate an important beneficial effect of stretching applied every 3 days to skeletal muscles and demonstrate that the stretching protocol used was effective in inducing sarcomere formation. As far as we know, this is the first demonstration that the effect of this protocol of passive stretching was evaluated in muscles immobilized in a shortened position and also in normal nonimmobilized muscles of rodents.

The decreased body weight found in the immobilized animals was probably due to the disuse and muscle atrophy caused by hind limb immobilization. A similar reduction in body weight was reported in studies involving muscle immobilization (3). Also, some factors have been pointed out to explain the weight loss associated with immobilization, such as small food intake because of the movement limitation, a possible decrease of body protein synthesis as a response to hypoactivity or a certain degree of stress $(9,18,26)$. In contrast, non-immobilized animals submitted to stretching sessions showed no changes in body weight during the experiment, as previously reported by Stauber et al. (27).

An interesting study carried out by Williams (3) showed that daily sessions of passive stretching for $30 \mathrm{~min}$ applied to the soleus muscle of mice immobilized in the shortened position were sufficient not only to prevent the loss of sarcomeres and to maintain the range of joint motion, but also caused an increase in the number of serial sarcomeres. However, short periods of stretching (15 min) applied every two days during immobilization were not sufficient to prevent the loss of serial sarcomeres and the range of joint movement (2). The author concluded that a minimum period of time is necessary during which the tension must be maintained for the adaptive process to start. The present results support this conclusion by demonstrating that three 40-min sessions of stretching applied to the soleus immobilized in a shortened position were not sufficient to prevent the loss of serial sarcomeres, but caused some positive regulation of the process of muscle fiber adaptation, attenuating the loss of the cross-sectional area. Gomes et al. (28) also found that stretching once a week was enough to attenuate the loss of cross-sectional area in the soleus muscle immobilized in the shortened position.

The present results also suggest that muscle stretching regulates in different ways the serial sarcomere number and the crosssectional area of the muscle fibers. More studies will be necessary to understand why the stretching sessions caused significant protection of the cross-sectional area but not against the serial loss of sarcomeres. Some studies have demonstrated that the neuronal isoform of neuronal nitric oxide synthase is involved in the regulation of the serial sarcomere number $(29,30)$. Chang et al. (29) showed that neuronal nitric oxide synthase is particularly concentrated at the muscletendon junction and is positively regulated by mechanical stimuli such as static stretching, thus possibly acting as a mechanotransducer for serial sarcomere addition (31). Neuronal nitric oxide synthase may also influence the synthesis of cytoskeletal proteins such as $\alpha$-actin (32), and/or satellite cell fusion at the ends of muscle cells, which occurs during sarcomere addition (6,33). Calcineurin, a cytoplasmic calcium-regulated phosphatase, has emerged as a possible candidate in the signaling of skeletal muscle hypertrophy (34), but is not likely to directly regulate skeletal muscle hypertrophy. A prominent role has been suggested for insulin-like growth factor 1 by activating the phosphatidyl-inositol 3-kinase-Akt (a serinethionine kinase) signaling circuit in this process $(27,35)$. 
In terms of the effect on sarcomere length, the present results showed that the muscles of both the immobilized and immobilized/ stretched groups presented increased sarcomere lengths, with no difference between them. The increased sarcomere length in shortened muscles has been associated with the reduction of serial sarcomere number, which involves an adjustment in the sarcomere length for the muscle to develop its maximal tension (4). Thus, in muscles immobilized in the shortened position, sarcomeres are lost and the remaining sarcomeres are pulled to a length that enables the muscle to develop its maximum tension in the immobilized position (4). Our results confirm this interpretation because both groups of immobilized muscles submitted or not to stretching presented a similar decrease in serial sarcomere number, as well as an equivalent increase in sarcomere length.

The presence of regeneration signals observed in the contralateral muscles of immobilized animals can be explained by the compensatory overloading on the non-immobi- lized hind limbs, as described previously $(36,37)$. Centrally located nuclei indicate that satellite cells are being activated and are involved in muscle regeneration or repair, as opposed to atrophy per se. Split fibers may also indicate regeneration (16). Thus, in the present study the contralateral muscles are not a completely appropriate control.

In conclusion, stretching applied every 3 days to immobilized muscles did not prevent the muscle shortening, but reduced muscle atrophy, suggesting that muscle stretching differently regulates the serial sarcomere number and cross-sectional area of muscle fibers. Stretching sessions also induced hypertrophic effects in the control non-immobilized muscles. These results support the use of muscle stretching in sports and rehabilitation.

\section{Acknowledgments}

The authors are grateful to Tereza F. Piassi for technical assistance.

\section{References}

1. Goldspink DF (1977). The influence of immobilization and stretch on protein turnover of rat skeletal muscle. Journal of Physiology, 264: 267-282

2. Williams PE (1988). Effect of intermittent stretch on immobilised muscle. Annals of the Rheumatic Diseases, 47: 1014-1016.

3. Williams PE (1990). Use of intermittent stretch in the prevention of serial sarcomere loss in immobilized muscle. Annals of the Rheumatic Diseases, 49: 316-317.

4. Williams PE \& Goldspink G (1978). Changes in sarcomere length and physiological properties in immobilized muscle. Journal of Anatomy, 127: 459-468.

5. Gamrin L, Berg HE, Essen P, Tesch PA \& Hultman E (1998). The effect of unloading protein synthesis in human skeletal muscle. Acta Physiologica Scandinavica, 163: 369-377.

6. Williams PE \& Goldspink G (1971). Longitudinal growth of striated muscle fibers. Journal of Cell Science, 9: 751-761.

7. Zemková H, Teisinger J, Almon RR, Vejsada R, Hník P \& Vyskocil F (1990). Immobilization atrophy and membrane properties in rat skeletal. Pflügers Archive. European Journal of Physiology, 16: 126-129.

8. Herbert RD \& Balnave RJ (1993). The effect of position of immobilization on resting length, resting stiffness, and weight of the soleus muscle of the rabbit. Journal of Orthopaedic Research, 11: 358-366.
9. Kannus P, Jozsa L, Järvinem TLN, Kvist M, Vienot T, Järvinen TAH, Natri A \& Järvinem M (1998). Free mobilization and low- to highintensity exercise in immobilization-induced muscle atrophy. Journal of Applied Physiology, 84: 1418-1424.

10. Feland JB, Myrer JW, Schulthies SS, Fellingham GW \& Measom GW (2001). The effect of duration of stretching of the hamstring muscle group for increasing range of motion in people aged 65 years or older. Physical Therapy, 81: 1111-1117.

11. Gajdosik RL (2000). Passive extensibility of skeletal muscle: Review of the literature with clinical implications. Clinical Biochemistry, 16: 87-101.

12. Goldspink G, Williams P \& Simpson H (2002). Gene expression in response to muscle stretch. Clinical Orthopaedics and Related Research, 403: 146-152.

13. Goldspink G (1999). Selective gene expression during adaptation of muscle in response to different physiological demands. Comparative Biochemistry and Physiology. Part B, Biochemistry and Molecular Biology, 120: 5-15.

14. Antonio J \& Gonyea WJ (1993). Progressive stretch overload of skeletal muscle results in hypertrophy before hyperplasia. Journal of Applied Physiology, 75: 1263-1271.

15. Antonio J \& Gonyea WJ (1993). Role of muscle fiber hypertrophy 
and hyperplasia in intermittently stretched avian muscle. Journal of Applied Physiology, 74: 1893-1898.

16. Antonio J \& Gonyea WJ (1994). Muscle splitting in stretch-enlarged avian muscle. Medicine and Science in Sports and Exercise, 26: 973-977.

17. Coutinho EL, Gomes ARS, França CN \& Salvini TF (2002). A new model for the immobilization of the rat hind limb. Brazilian Journal of Medical and Biological Research, 35: 1329-1332.

18. Ansved T (1995). Effects of immobilization on the rat soleus muscle in relation to age. Acta Physiologica Scandinavica, 154: 291-302.

19. William PE, Catanese T, Lucey EG \& Goldspink G (1988). The importance of stretch and contractile activity in the prevention of connective tissue accumulation in muscle. Journal of Anatomy, 158: 109-114.

20. Tardieu C, Tabary JC, Tabary C \& Huet de La Tour E (1977). Comparison of the sarcomere number adaptation in young and adult animals. Journal of Physiology, 73: 1045-1055.

21. Matano T, Tamai K \& Kurokawa T (1994). Adaptation of skeletal muscle in limb lengthening: a light diffraction study on the sarcomere length in situ. Clinical Orthopaedics and Related Research, 12: 193-196.

22. Tamai K, Kurokawa T \& Matsubara I (1989). In situ observation of adjustment of sarcomere length in skeletal muscle under sustained stretch. Nippon Seikeigeka Gakkai Zasshi. Journal of the Japanese Orthopaedic Association, 63: 1558-1563.

23. Salvini TF, Morini CC, Araujo HSS \& Ownby CH (1999). Long-term regeneration of fast and slow murine skeletal muscles after induced injury by ACL myotoxin isolated from Agkistrodon contortrix laticinctus (Broad-Banded Copperhead) venom. Anatomical Record, 254: 521-533.

24. Oliveira NML, Parizzotto NA \& Salvini TF (1999). GaAs (904-Nm) Laser radiation does not affect muscle regeneration in mouse skeletal muscle. Lasers in Surgery and Medicine, 25: 13-21.

25. Minamoto VB, Bunho SR \& Salvini TF (2001). Regenerated skeletal muscle of rat after periodic contusions. Brazilian Journal of Medical and Biological Research, 34: 1447-1452.

26. Shaffer MA, Okereke E, Esterhai Jr JL, Elliott MA, Walter GA \& Yim $\mathrm{SH}$ (2000). Effects of immobilization on plantar-flexion torque, fatigue resistance, and functional ability following an ankle fracture. Physical Therapy, 80: 1-16.
27. Stauber WS, Miller GR, Grimmett JG \& Knack KK (1994). Adaptation of rat soleus muscle to 4 weeks of intermittent strain. Journal of Applied Physiology, 77: 58-62.

28. Gomes ARS, Coutinho EL, França CN, Polonio J \& Salvini TF (2004). Effect of one stretch a week applied to the immobilized soleus muscle on rat muscle fiber morphology. Brazilian Journal of Medical and Biological Research, 37: 1473-1480.

29. Chang WJ, lannaccone ST, Lau KS, Masters BS, McCabe TJ, McMillan K, Padre RC, Spencer MJ, Tidball JG \& Stull JT (1996). Neuronal nitric oxide synthase and dystrophin-deficient muscular dystrophy. Proceedings of the National Academy of Sciences, USA, 93: 9142-9147.

30. Koh TJ \& Tidball W (1999). Nitric oxide synthase inhibitors reduce sarcomere addition in rat skeletal muscle. Journal of Physiology, 519: 189-196

31. Tidball JG, Lavergne E, Lau KS, Spencer MJ, Stull JT \& Wehling M (1998). Mechanical loading regulation regulates NOS expression and activity in developing and adult skeletal muscle. American Journal of Physiology, 224: 231-244.

32. Bishopric NH, Javaseka V \& Webster KA (1992). Positive regulation of the skeletal $\alpha$-actin gene by fos and jun in cardiac myocytes. Journal of Biological Chemistry, 267: 25535-25540.

33. Dix DJ \& Eisenberg BR (1990). Myosin mRNA accumulation and myofibrillogenesis at the myotendinous junction of stretched muscle fibers. Journal of Cell Biology, 111: 1885-1894.

34. Dunn SE, Burns JL \& Michel RN (1999). Calcineurin is required for skeletal muscle hypertrophy. Journal of Biological Chemistry, 274: 21908-21912.

35. Parsons SA, Millay DP, Wilkins BJ et al. (2004). Genetic loss of calcineurin blocks mechanical overload-induced skeletal muscle fiber type switching but not hypertrophy. Journal of Biological Chemistry, 279: 26192-26200.

36. Yang SY, Alnaqeeb M, Simpson H \& Goldspink G (1997). Changes in muscle fiber type, muscle mass and IGF gene expression in rabbit skeletal muscle subjected to stretch. Journal of Anatomy, 190: 613622.

37. Lieber RL (1992). Skeletal Muscle Structure and Function: Implications for Rehabilitation and Sports Medicine. Williams \& Wilkins, Baltimore, MD, USA. 